\title{
Aqui, o rádio de lá: uma análise his- tórica das influências estrangeiras nas emissoras brasileiras ${ }^{1}$
}

\section{Luiz Artur Ferraretto*}

Resumo: Análise histórica das influências estrangeiras sofridas pela programação das emissoras brasileiras ao longo do século 20, pretendendo demarcá-la dentro da ideia de que a indústria de radiodifusão sonora orientou-se em um quadro econômico nacional crescentemente subordinado às articulações do capitalismo em nível mundial. Procura-se, ainda, evidenciar os elementos oriundos do exterior, em especial dos Estados Unidos, presentes no rádio do país.

Palabras Clave: Rádio. História do rádio. Programação radiofônica.

Resumen: Un analisis historico de las influencias estrangeras sufridas por la programación de las emisoras brasileñas al largo del siglo 20, intentando inserirla en la idea de que la industria de la radiodifusión sonora se ha orientado en un cuadro económico nacional crescentemente subordinado a las articulaciones del capitalismo en nivel mundial. Se pretende, también, evidenciar los elementos originados en el exterior, en especial en Estados Unidos, presentes en la radio de Brasil. Palavras-chave: Radio. Historia de la radio. Programación radiofónica.

Abstract: Historical analysis of foreign influences experienced by the programming of brasilian radio stations throughout the 20th century, intending to demarcate it within the idea that the radio broadcasting industry has turned into a national economic scenario increasingly subordinated to the relations of global capitalism. The article also intent to show the elements coming from foreign countries, especially the United States, present on brasilian radio. Key words: Radio. Radio history. Radio programming. 
"Emissoras de ondas médias e curtas da Rádio Nacional, do Rio de Janeiro, Brasil." O locutor de voz pausada respira fundo e pronuncia com clareza, anunciando: "Alô, alô, Repórter Esso". A voz dá lugar à trilha musical característica composta pelo maestro Carioca e gravada junto com o baterista Luciano Perrone e os pistonistas Francisco Sergi e Marino Pissiali. Na sequência, Heron Domingues lê o texto, que ele e milhares de pessoas em todo o Brasil sabem de cor: "Prezado ouvinte, bom dia. Aqui fala o Repórter Esso, testemunha ocular da história, apresentando as últimas notícias da UPI".

Esta situação comum no rádio brasileiro dos anos 1950 traz em si quatro aspectos que evidenciam a influência estrangeira neste meio massivo de comunicação. $\mathrm{O}$ mais pueril talvez seja a utilização da palavra "alô", versão aportuguesada do "hello", comum nas aberturas de transmissões oriundas dos Estados Unidos e que, captadas em terras do Brasil, levaram à assimilação desta interjeição pelos primeiros radialistas tupiniquins. O mais conhecido é, sem dúvida, a introdução do modelo informativo das sínteses noticiosas com um texto direto, conciso e sem adjetivação. $\mathrm{O}$ mais economicamente capitalista deles está presente na inserção da técnica mercadológica representada pela associação direta do anunciante - a Standard Oil Company of Brazil, mais tarde Esso Brasileira de Petróleo - com o produto que serve de transporte à sua mensagem publicitária - neste caso, um noticiário. O mais evidente, em termos políticos a ser levado em conta, no entanto, constitui-se no uso manipulativo da mensagem dentro da esfera de interesse da principal potência do planeta.

Neste último aspecto, mais ideológico, cabe lembrar que a Standard pertencia ao clã dos Rockefeller e que o Esso entra no ar em 1941, durante a Segunda Guerra Mundial e dentro da chamada Política de Boa Vizinhança capitaneada pelo Office for Coordination of Commercial and Cultural Relations between the Americas. Quem dirigia e aparecia como uma espécie de ideólogo deste órgão do governo dos EUA era - coincidentemente para provar que, neste tema, não existem coincidências - o milionário Nelson Aldrich Rockefeller (Cf. TOTA, 2000, p. 44-50).

Este exemplo inicial serve para demonstrar a gama de interrelações presentes no assunto básico deste breve ensaio: a influência estrangeira no rádio brasileiro. Trata-se de evidenciar o quanto da trajetória deste meio no Brasil apresenta de elementos oriundos do exterior, em especial dos Estados Unidos. Não se pretende, entretanto, dada a exi- 
guidade do espaço, julgar se esta influência foi ou é positiva ou negativa, mas sim se objetiva demarcá-la, considerando a possibilidade de que o rádio brasileiro orientou-se, ao longo do tempo, dentro de um contexto óbvio de economia nacional crescentemente subordinada às articulações do capitalismo em nível mundial. Da mesma forma, os fatos históricos aqui citados servem apenas como exemplos a atestar esta proximidade, tendo-se consciência de que existem vários outros além destes.

\section{Clubes e sociedades}

Entre abril de 1919 e fevereiro de 1923, em Recife, um grupo de radiófilos liderado por Augusto Joaquim Pereira e financiado pelo industrial José Cardoso Aires aprimora gradativamente as transmissões do Rádio Clube de Pernambuco, garantindo que estas alcancem o centro da cidade e algumas regiões próximas. Em 20 de abril de 1923, entusiastas ligados à Academia Brasileira de Ciências e reunidos em torno de Edgard Roquette-Pinto fundam a Rádio Sociedade do Rio de Janeiro que, em $1^{\text {o }}$ de maio, inicia suas irradiações. Nestas duas iniciativas pioneiras, o associativismo é marcado por dose expressiva de idealismo elitista misturado com curiosidade e deslumbramento técnico, noções que se dirigem a uma espécie de utopia de civilização. Para os integrantes destas agremiações, de um lado, cultura significa erudição sob a matriz referencial externa da época: a Europa ou, mais especificamente, a França; de outro, tecnologia é progresso relacionado, portanto, com modernização. Tal constatação vai ao encontro do que Renato Ortiz, em raciocínio semelhante, identifica em relação à urbanização do Rio de Janeiro e à introdução do cinema, quase no mesmo período, no início do século 20:

[...] a ideia de moderno se associa a valores como progresso e civilização; ela é, sobretudo, uma representação que articula o subdesenvolvimento da situação brasileira a uma vontade de reconhecimento que as classes dominantes ressentem. Daí o fato de essa atitude estar intimamente relacionada a uma preocupação de fundo, "o que diriam os estrangeiros de nós”, o que reflete não somente uma dependência aos valores europeus, mas revela o esforço de se esculpir um retrato do Brasil condizente com o imaginário civilizado (ORTIZ, 1994, p. 32). 
Cabe lembrar que, desde o início do século 20, cidades como Rio de Janeiro, São Paulo e Porto Alegre vivem um afã modificador do cenário urbano que auxilia na estruturação de um imaginário social da modernidade. Primeiro, aumentam os impostos sobre as moradias da região central, afastando a população mais carente para a periferia, e, na sequência, são construídos grandes prédios públicos ou espaçosas avenidas. Vale recordar, ainda, como a coroar este processo, o slogan de Washington Luiz Pereira de Sousa: "Governar é abrir estradas". Coincidentemente, é ele o presidente derrubado pela Revolução de 1930, que eclode como a expor as divergências intra-oligárquicas e, em plano menor, as incoerências do progresso de fachada dos anos anteriores.

Neste contexto, tem importância significativa a Exposição Internacional do Rio de Janeiro, inaugurada em 7 de setembro de 1922 em comemoração ao centenário da independência brasileira. Embora no discurso oficial do governo de Epitácio Pessoa houvesse a intenção manifesta de apresentar uma pretensa pujança econômica nacional atraindo libras esterlinas e dólares, eventos deste tipo e porte serviam, desde o século anterior, na realidade, para demonstrar a tecnologia de ponta, contrastando o mundo industrial moderno - das grandes potências - com um outro, mais agropecuário e mercantil - no caso específico, o do Brasil. Assim, o capital dava mostras daquela sua característica inata identificada por Karl Marx em Para a crítica da economia politica, de 1859:

Quanto mais desenvolvido o capital, quanto mais extenso é portanto o mercado em que circula, mercado que constitui a trajetória espacial de sua circulação, tanto mais tende simultaneamente a estender o mercado e a uma maior anulação do espaço através do tempo (apud IANNI, 1996, p. 138).

$\mathrm{Na}$ referida exposição, aquela "necessidade de um mercado em constante expansão para os seus produtos”, que persegue o capitalismo por todo o globo, fazendo com que "tenha de se fixar em toda a parte, estabelecer-se em toda a parte, criar ligações em toda a parte" (MARX; ENGELS, 1987, p. 37), está presente nos estandes de duas indústrias dos Estados Unidos: a Westinghouse International Company e a Western Electric Company, ambas com capacidade ociosa de produção desde o final da Primeira Guerra Mundial, em 1918, e procurando, por meio das demonstrações radiotelefônicas então realizadas, a obtenção de um novo 
mercado, o brasileiro. Estas transmissões, como se sabe, chamam a atenção de Roquette-Pinto e influenciam o surgimento da Rádio Sociedade do Rio de Janeiro. Também junto a uma delas, a Westinghouse, os entusiastas do Rádio Clube de Pernambuco adquirem um transmissor de $10 \mathrm{~W}$ responsável pela melhoria do sinal da estação a partir de fevereiro do ano seguinte.

É, deste modo, dentro de um quadro de subordinação cultural e tecnológica que vai surgindo o rádio no Brasil, um país que, em contraste, na virada do século 19 para o 20, abrigava experiências pioneiras de radiotelefonia e radiotelegrafia levadas a cabo por Roberto Landell de Moura, mas praticamente ignoradas pelas autoridades de então, embora, por vezes, presenciadas por representantes de governos estrangeiros como o da GrãBretanha, principal potência daquela época (cf. FORNARI, 1960, p. 12).

\section{Rádio espetáculo}

No início dos anos 1920, os amadores da radiotelefonia, semfilistas ou radiófilos - como são chamados pela imprensa da época - gastam suas noites em frente aos grandes, pesados e caros aparelhos receptores da época. Um dos bons com três ou quatro válvulas, custando 400 mil-réis, o dobro do que ganha, então, em média, um assalariado, consegue sintonizar emissões de particulares e comunicações navais, não importando se telefônicas ou telegráficas. O objetivo maior, no entanto, é ouvir irradiações de estações como KDKA, de Pittsburgh, ligada à Westinghouse, e WEAF, de Nova Iorque, da American Telephone and Telegraph, mais facilmente captadas nas regiões Norte e Nordeste, ou LOR - Asociación Argentina de Broadcasting, LOW - Grand Splendid Theatre, LOS - Broadcasting Municipalidad e LOO - Radio Prietto, de Buenos Aires, e El Día, de Montevidéu, no Sul e Sudeste.

$\mathrm{Na}$ década seguinte, irradiações como estas servem ainda de referencial. Ouvindo a NBC, dos Estados Unidos, e a britânica BBC, em ondas curtas, Adhemar Casé observa uma diferença significativa em relação ao rádio brasileiro da época:

O amadorismo das rádios daqui não permitia uma dinâmica maior. Quando um músico e um cantor iam se apresentar, o speaker anunciava o número e, depois, desligava o microfone, para que pudessem afinar os instrumentos e até fazer um rápido ensaio. Enquanto isso, o ouvinte ficava totalmente 
abandonado. Já nos programas americanos, o som não parava. Era uma dinâmica maravilhosa (apud CASÉ, 1995, p. 39).

Com esta inspiração, ele aluga o horário dominical das $20 \mathrm{~h}$ à meia-noite na Rádio Philips, emissora mantida pela indústria holandesa de mesmo nome no Rio de Janeiro, estreando, no dia 14 de fevereiro de 1932, o Programa Casé, base de atrações semelhantes surgidas nos anos seguintes. Paralelamente, César Ladeira, em São Paulo, organiza a programação da Record, introduzindo o cast profissional e exclusivo, com remuneração mensal, embrião da subsequente estruturação - em especial, na década de 1950 - de uma espécie de star system tupiniquim, uma cópia subdesenvolvida de seu correspondente hollywoodiano e que, aqui, se manifesta nos programas de auditório, no radioteatro e nos humorísticos. Tal sistema abrange, até meados da década de 50 , também a indústria cinematográfica com as produções da Cinédia, inicialmente, e da Atlântida, de larga penetração junto ao público. É importante destacar os números musicais apresentados nos filmes que ganham divulgação nas emissoras de rádio e, em conjunto, impulsionam a produção e a comercialização de discos, processo que ocorre também em sentido contrário.

Hollywood, aliás, consolida-se como referência de entretenimento durante a Segunda Guerra Mundial, período em que a chamada Política de Boa Vizinhança incentiva intercâmbios de astros e estrelas dos Estados Unidos com países da América Latina, os quais interessa a Washington ter, sob sua influência política e econômica, marchando, na época, militarmente ao seu lado contra a Alemanha nazista, a Itália fascista e o Japão imperialista e, após o conflito, mantendo-se do lado do chamado mundo livre em oposição à União Soviética comunista. Na primeira metade dos anos 1940, cabe ao rádio brasileiro papel significativo no processo de transposição e valorização do chamado American way of life no país.

No contexto do conflito armado que envolve o planeta, são os alemães e os italianos que usam primeiro a radiodifusão sonora como arma propagandística. Em 1932, começa a operar em ondas curtas a estação DJA da Transmissora Nacional Alemã, instalada em Berlim, com irradiações em português, espanhol e alemão. Três anos depois, em 1935, iniciam as emissões do Ente Italiano Audições Radiofônicas, divulgando, direto de Roma, as atividades fascistas. Dados do arquivo federal da Alemanha confirmam que o Terceiro Reich manteve uma rede de radiodifusão com 15 emissoras em operação no Brasil, entre elas a Ipanema, do Rio de Janeiro, totalmente controlada por agentes do Eixo. 
Em oposição à presença propagandística ítalo-germânica, os Estados Unidos criam o já citado Office for Coordination of Commercial and Cultural Relations between the Americas, órgão gestor da chamada Política de Boa Vizinhança. É a sua Divisão de Rádio que estrutura toda uma programação reproduzida em diversas emissoras do Brasil. Nestas irradiações, os produtores esforçam-se para demonstrar afinidades entre os dois países irmanados na luta contra o nazi-fascismo. Em paralelo, difundem o American way of life, caracterizado fortemente pela economia de mercado e pela livre iniciativa empreendedora, fatores que embasam uma sociedade em tese igualitária pela possibilidade de todos - independente de classe social - terem acesso ao consumo.

Neste sentido, o círculo mercantil capitalista depende da comunicação empresa-consumidor, viabilizada pelo rádio desde a década de 1930, época em que começam a se instalar no país grandes agências de publicidade com sede nos Estados Unidos ou inspiradas nas suas congêneres daquele país: N. W. Ayer, J. Walter Thompson, Standard e McCann-Erickson. Por meio delas, são introduzidas técnicas então comuns nos EUA:

1. Veiculação de spots, tipo de texto publicitário breve, podendo utilizar música ou efeitos sonoros, mas com a sua força recaindo sobre o poder da palavra falada, e jingles, mensagem comercial de curta duração na forma de uma música simples e cativante, fácil de cantarolar e recordar.

2. Associação do nome de um produto ao do programa, como no caso do Repórter Esso.

3. Utilização de promoções, como a idealizada pela Standard para o creme dental Colgate, patrocinador de Em busca da felicidade. Os rótulos do produto davam direito a fotos de artistas e álbuns com o resumo da primeira radionovela transmitida no país. No primeiro mês, 48 mil cartas chegam aos estúdios da Rádio Nacional, volume de pedidos que inviabiliza a continuidade da promoção.

4. Uso de programas para lançamento de produtos. Um forte exemplo é a relação de $U m$ milhão de melodias com o refrigerante Cocacola.

Este último merece especial atenção. Além de seguir um esquema comum do rádio dos EUA, o dos programas musicais conduzidos por bigbands como a de Benny Goodman, Um milhão de melodias estreia, em 1943, na Nacional, do Rio de Janeiro, sob o patrocínio de Coca-cola, produto que ingressa, então, no mercado brasileiro. A cada semana, a orquestra conduzida pelo maestro Radamés Gnatalli interpreta um repertório de músicas novas e antigas, destacando-se sempre três grandes sucessos estrangeiros 
No ar até 1950 e retornando, dois anos depois, para um novo período de transmissões até 1953, Um milhão de melodias inicia o período de hegemonia musical estadunidense no país. A fórmula é copiada em outras atrações radiofônicas. Desde modo, pode-se dizer que esta atração difunde a trilha sonora do American way of life associada, no caso específico, a um dos seus combustíveis, Coca-cola.

Outro exemplo é o já citado Repórter Esso, espécie de porta-voz radiofônico do interesse estadunidense. Transmitido a partir de 1941, quando o Brasil ainda não havia declarado guerra aos países do Eixo, o informativo permanece no ar até 1968 . O papel do Esso não se altera com o fim do conflito mundial, em 1945, e o encerramento das atividades, um ano depois, do órgão gestor da Política de Boa Vizinhança, então conhecido como Office of the Coordinator of Commerce and Cultural Relations between the American Republics. Na década de 1950, durante a campanha do Petróleo é Nosso, por exemplo, o informativo nada noticia, fiel aos objetivos da Esso, temerosa com a possibilidade de o surgimento da Petrobrás diminuir a sua parcela no mercado de combustíveis.

Também na radiodramaturgia faz-se notar a marca da influência estrangeira. Neste aspecto, ocorre, por vezes, uma espécie de triangulação. De início, dos Estados Unidos, vem o patrocinador. De Cuba, principalmente, ou do México, o conteúdo a ser irradiado. Ao Brasil cabe o papel de mercado a ser conquistado. É o que acontece com Em busca da felicidade, do cubano Leandro Blanco, adaptada por Gilberto Martins. Não só a radionovela pioneira originou-se da verve caribenha, mas também o maior sucesso do gênero no país: $O$ direito de nascer, de Félix Caignet, um dos precursores da literatura radiofônica latino-americana (cf. LỎPEZ, 1998, p. 495-510). A importação destes folhetins pode ser explicada pela ideia comum do ponto de vista ianque - de que, abaixo do rio Grande, não havia muita diferença entre as American republics, não interessando se falavam espanhol ou português, se dançavam rumba, tango ou samba.

Nos auditórios dos anos 1950, surgem ainda programas de perguntas e respostas copiados ou importados diretamente do rádio dos Estados Unidos. Os Diários e Emissoras Associados, de Francisco de Assis Chateaubriand Bandeira de Mello, detêm, por exemplo, os direitos para o Brasil de $O$ céu é o limite, quiz-show aproveitado na programação da TV Tupi, de São Paulo, e da Rádio Farroupilha, de Porto Alegre.

O rádio espetáculo das novelas, auditórios e humorísticos atinge, nesta época, seu apogeu. O país vive o desenvolvimentismo do governo de Juscelino Kubitschek de Oliveira com o Estado incentivando o investi- 
mento estrangeiro, em especial para a indústria automotiva. $\mathrm{O}$ capitalismo brasileiro começa, inserindo-se mais e mais na economia mundial, a assumir uma face monopólica, assim definida por Paul Singer:

O que distingue o capitalismo monopólico do da fase anterior - denominado de competitivo ou liberal - é antes de mais nada a mudança nas regras da competição. Nos mercados competitivos, numerosas empresas disputam a preferência dos compradores mediante preços mais baixos ou vantagens análogas, tais como prazos mais longos de pagamento, descontos etc. Nos mercados monopólicos, a preferência dos compradores é disputada por pequeno número de grandes firmas mediante diferenciação dos produtos, prestígio da marca e publicidade. $\mathrm{O}$ público consumidor é persuadido de que a marca e a aparência do produto representam qualidade superior e, portanto, justificam o pagamento de um preço mais alto (SINGER, 1987, p. 75).

A radiodifusão sonora vai ganhar status de indústria cultural ao longo de um processo que se concretiza nos anos 1970 capitaneado pelas redes nacionais de televisão em um quadro no qual grandes conglomerados procuram exercer a propriedade cruzada de meios de comunicação impressos e eletrônicos. A formação e consolidação destes grupos vai ao encontro do que Singer descreve como característico do capitalismo monopólico. Antes disto, o Brasil assiste à derrubada do presidente João Goulart em 1964, pondo fim a quase duas décadas de regime democrático no país. É com o chamado milagre econômico, na época do "Brasil: ame-o ou deixe-o", que começa a se estruturar uma sociedade de consumo no país, básica para a instauração da indústria cultural em toda a sua complexidade.

\section{Rádio segmentado}

Nos anos 1960, é do Departamento de Defesa dos Estados Unidos, o conhecido Pentágono, que vem a doutrina de segurança nacional segundo a qual um conflito permanente opõe o Ocidente cristão ao Leste ateu e comunista. Escaldada pela declaração do caráter socialista da Revolução Cubana, a política externa da principal potência das Américas incentiva e apóia a instauração da ditadura militar no Brasil. Amparados neste mesmo conceito de se- 
gurança nacional, os militares tupiniquins interligam o país via telecomunicações. Ainda na segunda metade da década, começam a incentivar a instalação de emissoras de rádio em frequência modulada para "integrar e desenvolver o país" e "resguardar o território nacional e os valores culturais" no combate à penetração de emissoras estrangeiras, em especial aquelas que denunciavam a repressão (cf. DEL BIANCO, 1993, p. 142).

As emissoras em frequência modulada, no entanto, crescem somente quando o rádio brasileiro descobre o ouvinte jovem. Isto acontece a partir de maio de 1977, com a entrada no ar da Cidade FM, do Rio de Janeiro. A inspiração vem das rádios musicais dos Estados Unidos. Com o sucesso de diversas estações que copiam este novo perfil, a faixa cresce de importância em termos de participação no bolo publicitário. Estações em AM e FM começam, então, a buscar nichos específicos no mercado, o que inicia o processo de segmentação.

Desde a década anterior, o rádio vivia a crise provocada pela introdução da TV e seu posterior crescimento em audiência e comercialização publicitária. O governo militar tinha inserido na administração pública a figura do tecnocrata, o burocrata técnico por excelência. Esta especificidade da política governamental reflete-se na indústria cultural. Como observa Ortiz, usando conceitos desenvolvidos por Fernando Henrique Cardoso, ocorre a transição dos capitães de indústria, dirigentes pautados pela obtenção de favores governamentais para a manutenção de seus empreendimentos, para os homens de empresa, orientados por uma visão gerencial voltada à consolidação da iniciativa privada (cf. ORTIZ, 1994, p. 134/ CARDOSO, 1972, p. 142).

Neste sentido, os empresários brasileiros do setor passam a frequentar, na década de 1970, os encontros da indústria radiofônica dos Estados Unidos. É em um congresso do Radio Advertising Bureau, em Las Vegas, no ano de 1972, por exemplo, que Nelson Pacheco Sirotsky, mais tarde diretor-presidente do Grupo RBS, toma contato com os formatos radiofônicos all talk e all news ${ }^{2}$, cuja aplicação em uma emissora até então de programação indefinida, a Gaúcha, de Porto Alegre, vai transformá-la em uma das principais do país nas décadas seguintes. Nos meetings e nas conventions, com destaque para as da National Association of Broadcasters, vai se forjando o novo modelo gerencial do rádio brasileiro com diretores, gerentes e coordenadores divididos por áreas e tornando comum em seu dia-a-dia termos e expressões como marketing, merchandising e survey. Neste último caso, o planejamento baseado em pesquisas de audiência norteia as ações em um mercado cada vez mais competitivo e segmentado, que, 
diferentemente da América do Norte, enfrenta as constantes oscilações de uma economia subdesenvolvida como a do Brasil.

\section{Rádio convergente}

Entre o empresariado brasileiro, a exemplo do estadunidense, mas com a natural defasagem entre a economia de Primeiro e a de Terceiro Mundo, a segunda metade dos anos 1990 viu começar a discussão sobre a necessidade de migração da tecnologia analógica para a digital. Logo de início, nas manifestações de representantes do setor, houve uma clara inclinação para que o Brasil adota-se o sistema atualmente conhecido como HD Radio, apresentado, em um primeiro momento, com uma denominação bem explicativa - a sigla IBOC, de "in-band, on-channel" - a indicar a manutenção dos canais atuais que, apenas, trocariam de tecnologia, ganhando qualidade sonora e serviços adicionais (por exemplo, informações de texto no display do receptor). Seria o único, em um discurso que chegou a ser assumido pelo Ministério das Comunicações, capaz de manter as características dominantes e comerciais do rádio brasileiro, neste aspecto muito semelhante ao dos Estados Unidos.

Ao terminar a primeira década do século 21, com outros sistemas IBOC - como o europeu DRM - em desenvolvimento e sendo testados no Brasil, o debate em torno do rádio digital parece, indicam os fatos, ter sido superado pelas preocupações geradas pela convergência, este processo de simbiose entre a comunicação de massa tradicional (imprensa, rádio e TV) e formas comunicacionais agora já consolidadas ou em rápida fase de consolidação (a TV por assinatura, a telefonia móvel e a internet). $\mathrm{Na}$ matriz situada ao norte do continente americano, como destaca Nélia Del Bianco (2009, f. 9.), de um total de 13 mil emissoras, apenas 1,8 mil haviam adotado o HD Radio até 2009, enquanto, no que diz respeito aos ouvintes, a situação é ainda pior: em uma população de 300 milhões, existem $450 \mathrm{mil}$ com receptores digitais.

Quinze anos após a internet ter adquirido, no Brasil, feições comerciais e, cada vez mais, massivas, e quase duas décadas depois da introdução da telefonia celular no país, começa a se tornar dominante, pelo menos entre os principais grupos comunicacionais, a noção de que o rádio deve ir além das ondas eletromagnéticas, marcando presença nas mais diversas formas de transmissão e recepção. Neste cenário, buscam-se novas brechas 
de mercado com base também no mercado estadunidense. Um exemplo são as estratégias de branded content: em vez de programas patrocinados por grandes marcas, estações rebatizadas inauguram a comunicação direta empresa-consumidor (Oi FM, Sulamérica Paradiso FM, Mitsubishi FM). Nesta linha, o início das operações da Disney FM, em São Paulo, no mês de novembro de 2010, é o exemplo mais recente e, pela carga simbólica da marca que carrega, também o mais significativo.

Bem antes, no final do século 20, grandes grupos de comunicação ensaiam movimentos no cenário da convergência - mídia tradicional, telecomunicações e informática. Os altos e baixos deste processo atestam a debilidade do capital nacional no contexto da globalização econômica. Marco desta realidade são as dificuldades do Grupo RBS, com sede em Porto Alegre, em sua parceria com a Telefónica de España, rompida quando esta última decidiu unilateralmente participar do leilão da então estatal Telecomunicações de São Paulo. (Telesp). Como consequência, o conglomerado controlado pela família Sirotsky enfrentou dificuldades financeiras, saiu da Companhia Rio-grandense de Telecomunicações e perdeu a Tele Centro Sul, seu objetivo estratégico dentro do leilão de privatização do Sistema Telebrás.

\section{Considerações finais}

Os dados elencados, como exposto no início deste ensaio, são indicativos para reflexão, demarcando, no campo da indústria de radiodifusão sonora, a influência estrangeira, em especial dos Estados Unidos, sobre o Brasil. Seria, é claro, ingenuidade crer em situação muito diferente desta, dada a dependência histórica do país em relação ao seu principal parceiro econômico, fora, por óbvio, a influência cultural, presente, por exemplo, em parcela significativa da programação musical. Esta ascendência não significa, no entanto, que o rádio brasileiro não possui expressão própria, mas sim que este apresenta boa dose de elementos comuns ao que se faz nas emissoras da principal potência do planeta. É uma influência tão forte que mesmo em rádios autodefinidas como comunitárias aparecem formas de um fazer radiofônico próprio das emissoras jovens em sua concepção estadunidense: o DJ falando rápido, quase gritando e tocando músicas de sucesso fácil e em inglês.

Pode-se dizer que, de início, na radiodifusão sonora, predomina 
total subordinação tecnológica e tênue influência em termos de conteúdo. Nos anos 1930, ressalvando os casos já referidos protagonizados por Adhemar Casé e, mesmo, César Ladeira, as emissoras ocupam sua programação com atrações locais, marcadamente de música popular brasileira, apesar da presença de ritmos estrangeiros. Com o agravamento da Segunda Guerra Mundial, a influência pende para o político, refletindo-se no rádio o processo de americanização e esboçando-se, como resultado, uma espécie de star system caboclo que vigora até a consolidação das primeiras estações de televisão. $\mathrm{Na}$ sequência, com a economia brasileira inserida no sistema internacional capitalista e existindo no país um consumo que a sustente, instaura-se uma indústria cultural com fortes traços econômicos e gerenciais estadunidenses.

É necessário ressalvar ainda que influência não significa a aplicação sem adaptações ${ }^{3}$ de estratégias gerenciais, concepções de programação, metodologias de trabalho etc. Em todos os aspectos do fazer radiofônico, a tendência é que ocorram, ao longo deste processo, ajustes à realidade nacional.

\section{Referências}

ALCIDES, Jota. PRA-8, o rádio no Brasil. Brasília: Fatorama, 1997.

ANDERSON, Carter. Nas ondas do Reich. O Globo, Rio de Janeiro, 21 jan. 2001. Disponível em: <http://oglobo.globo.com/arquivo/ pais/20010121/pais80.htm>. Acesso em: 23 jan. 2001.

. Reich comprou a Rádio Ipanema em 1941. O Globo, Rio de Janeiro, 21 jan. 2001. Disponível em: <http://oglobo.globo.com/arquivo/ pais/20010121/pais60.htm.> Acesso em: 23 jan. 2001.

CARDOSO, Fernando Henrique. Empresário industrial e desenvolvimento econômico no Brasil. 2.ed. São Paulo: Difusão Europeia do Livro, 1972.

CASÉ, Rafael. Programa Casé, o rádio começou aqui. Rio de Janeiro: Mauad, 1995.

DEL BIANCO, Nélia Rodrigues. FM no Brasil 1970-79: crescimento incentivado pelo regime militar. Comunicação Eे sociedade, São Bernardo do Campo: Instituto Metodista de Ensino Superior, ano 12, n. 20, p. 133-147, dez. 1993. 
- O futuro do rádio no cenário da convergência frente às incertezas quanto aos modelos de transmissão digital. In: SOCIEDADE BRASILEIRA DE ESTUDOS INTERDISCIPLINARES DA COMUNICAÇÃO. $32^{\circ}$ Congresso Brasileiro de Comunicação. Curitiba, 5 set. 2009. $15 f$. Texto apresentado no Grupo de Pesquisa Rádio e Mídia Sonora.

FERRARETTO, Luiz Artur. Rádio no Rio Grande do Sul (anos 20, 30 e 40): dos pioneiros às emissoras comerciais. Canoas: Editora da Ulbra, 2002.

Rádio - O veículo, a bistória e a técnica. 3.ed. Porto Alegre: Doravante, 2007a.

- Rádio e capitalismo no Rio Grande do Sul: as emissoras comerciais e suas estratégias de programação na segunda metade do século 20 . Canoas: Editora da Ulbra, 2007b.

GONZALES, Demóstenes. O rádio a serviço da cultura. O céu é o limite, famoso programa, estreia hoje na Farroupilha. Diário de noticias, Porto Alegre, $1^{\circ}$ set. 1957 . p. 5. Suplemento.

IANNI, Octavio. Teorias da globalização. 3.ed. Rio de Janeiro: Civilização Brasileira, 1996.

KLÖCKNER, Luciano. O Repórter Esso: a síntese radiofônica mundial que fez história. Porto Alegre: AGE/ Editora da PUCRS, 2008.

LÓPEZ, Oscar Luis. La radio en Cuba. 2.ed. Havana: Letras Cubanas, 1998.

MARX, Karl; ENGELS, Friedrich. Manifesto do Partido Comunista. Moscou: Progresso, 1987.

MEDITSCH, Eduardo. Fatiando o público: o rádio na vanguarda da segmentação da audiência. Verso Ẽ Reverso, São Leopoldo: Editora da Unisinos, ano 16, n. 35, p. 55-60, jul.-dez. 2002.

MOREIRA, Sonia Virginia. O rádio no Brasil. Rio de Janeiro: Mil Palavras, 2000.

ORTIZ, Renato. A moderna tradição brasileira: cultura brasileira e indústria cultural. 5.ed. São Paulo: Brasiliense, 1994.

PESAVENTO, Sandra Jatahy. O espetáculo da rua. Porto Alegre: Editora da UFRGS/ Prefeitura Municipal de Porto Alegre, 1992. 
RAMOS, Ricardo. Do reclame à comunicação: pequena história da propaganda no Brasil. 3.ed. São Paulo: Atual, 1985.

SAROLDI, Luiz Carlos; MOREIRA, Sonia Virgínia. Rádio Nacional, o Brasil em sintonia. 2.ed. Rio de Janeiro: Martins Fontes/ Funarte, 1984.

SINGER, Paul. O capitalismo: sua evolução, sua lógica e sua dinâmica. 5.ed. São Paulo: Moderna, 1987.

TOTA, Antonio Pedro. O imperialismo sedutor: a americanização do Brasil na época da Segunda Guerra. São Paulo: Companhia das Letras, 2000.

\section{Notas}

[1] Uma versão deste texto foi apresentada em 7 de setembro de 2001 no então Núcleo de Pesquisa em Mídia Sonora durante o XXIV Congresso Brasileiro de Ciências da Comunicação, em Campo Grande.

[2] $\mathrm{O}$ all newws, em sua forma pura, implica repetição de notícias em uma seqüência de informativos e quadros - meteorologia, trânsito, mercado financeiro... - sucessivos. Por exemplo, transmitindo de Tijuana, no México, para o sul da Califórnia, em especial a cidade de Los Angeles, a XTRA, do empresário texano Gordon McLendon, que inaugura o formato em 6 de maio de 1961, veicula, de início, as principais notícias do momento a cada sete minutos e meio, intervalo, posteriormente, ampliado para meia hora. Já no all talk, a base é a conversação constante em programas de entrevistas, de opinião ou mesas-redondas, com ou sem a participação do ouvinte.

[3] Eduardo Meditsch (jul.-dez. 2002) faz alerta semelhante a respeito do uso de modelos de programação estadunidenses por emissoras brasileiras. 


\section{* Luiz Artur Ferraretto}

Doutor em Comunicação e Informação pela UFRGS e professor do Centro de Ciências da Comunicação da Universidade de Caxias do Sul (UCS).

\section{E-mail:}

luiz.ferraretto@uol.com.br. 